\title{
Cholinergic and Serotonergic Neural Links and the Inhibitory Effects of Hippocampus, Lateral Amygdala and Central Gray Matter on Gonadotropin Release
}

\author{
Masazumi KAWAKAMI, Fukuko KIMURA, \\ AND SHinnosuke KAWAGOE \\ 2nd Department of Physiology \\ Yokohama City University School of Medicine, Yokohama 232
}

\begin{abstract}
Synopsis
Effects of electrical stimulation of the hippocampus (HPC), lateral amygdala (1-AMYG) and midbrain central gray matter (CG) on the release of ovulatory gonadotropin were examined using proestrous Wistar rats with or without pretreatment with reserpine, atropine or p-chlorophenylalanine (PCPA) at such dosage that had been confirmed not to block ovulation. Electrical stimulation of the HPC, 1-AMYG or CG under light ether anesthesia just before the critical period prevented a rise in serum LH, FSH and prolactin levels at 18:00. Pretreatment with atropine $(200 \mathrm{mg} / \mathrm{kg}$ body $\mathrm{wt}, \mathrm{sc})$ was effective to abolish this inhibitory effect of the HPC stimulation on the release of $\mathrm{LH}$ and $\mathrm{FSH}$, whereas reserpine treatment $(1 \mathrm{mg} / \mathrm{kg}$ body wt, ip) did not affect the effect. The inhibitory effect of the 1-AMYG or CG stimulation on LH and FSH release was abolished by treatment with PCPA (150 $\mathrm{mg} / \mathrm{kg}$ body wt, ip), while neither atropine nor reserpine had any effect. The inhibitory effect of the HPC stimulation on the release of these hormones was also blocked by PCPA treatment. In regard to the prolactin release, it was inhibited by the stimulation of the HPC, 1-AMYG or CG in both the non-treated rat and in the atropine or PCPA-treated one, while in the reserpine-treated rat it was not inhibited but rather was facilitated by these stimulations.

It was assumed that the normal maintenance of both cholinergic and serotonergic neural links for the expression of the HPC inhibition on ovulatory LH, FSH and prolactin secretion and that of serotonergic link for the expression of the 1-AMYG or CG inhibition are needed. The inhibitory action on prolactin release changed into facilitation under the depletion of monoamines, but the mechanism is unknown.
\end{abstract}

It is apparent from the recent studies, that the forebrain limbic structure plays an important role in modulating the secretion of gonadotropins. Evidence has been presented that the hippocampus (Kimura and Kawakami, 1968, Velasco and Taleisnik, 1969 ; Kawakami et al.; 1973) and the lateral part of amygdala (Kawakami and Kimura, 1975a) exert an inhibitory influence on the release of gonadotropin. Carrer and Taleisnik (1970) have shown that the electro-

Received for publication September 10, 1975. chemical stimulation of some areas in the midbrain structures, the ventral tegmental area, the raphe nuclei and the central gray matter also influence the gonadotropin release in an inhibitory manner.

On the other hand, a large number of investigations have demonstrated an involvement of biogenic amines in the CNS regulation of gonadotropin secretion (see Reviews; Hökfelt and Fuxe, 1972; McCann et al., 1972 ; Coppola, 1971). The substances most generally accepted to serve as neurotransmitters somewhere in the brain include 
catecholamines, indolamines and acetylcholine. Most of information seems to support the concept that the catecholaminergic (see Review; Sawyer, 1975) and cholinergic (Everett et al., 1949; Sawyer et al., 1949; Libertun and McCann, 1973; Kamberi, 1973) systems have a facilitatory effect, whereas the indolaminergic (Labhsetwar, 1971; Kamberi et al., 1971; Schneider and McCann, 1970; Wilson and McDonald, 1974) system has an inhibitory effect on the release of LRF, FRF and PIF from the hypothalamus.

The present study was performed to know the mode of involvement of these biogenic amines in the expression of inhibitory action of limbic forebrain structure. The experiment investigated the influence of reserpine, atropine, and p-chlorophenylalanine on the inhibitory effects of electrical stimulation of the hippocampus, lateral amygdala and central gray matter on ovulatory gonadotropin release.

\section{Materials and Methods}

Adult female rats of Wistar strain, weighing 200$250 \mathrm{~g}$, were used in this study. All rats were caged in a light controlled room (lights on from 5:00 to 19:00) and supplied with food and water ad lib. Daily vaginal smears were taken in the morning and only rats in proestrus, which had shown at least 2 consecutive 4-day cycles, were employed.

In order to determine the dosage of each drug to be investigated, at which spontaneous ovulation is not blocked even when it was administered on the day of proestrus, atropine sulfate (Wako Purechemical Ind.) dissolved in $0.9 \%$ saline was injected sc at the dosage of $200,700 \mathrm{mg} / \mathrm{kg}$ body wt between $10: 30$ 11:00, and reserpine (Apoplon, Daiichi Seiyaku, $1.0 \mathrm{mg} / \mathrm{ml}$ ampoules) or p-chlorophenylalanine (PCPA, Tokyo Kasei Kogyo), the latter being suspended in $0.9 \%$ saline, was injected ip at the dosage of 1 , $2.5 \mathrm{mg} / \mathrm{kg}$ body wt or $150 \mathrm{mg} / \mathrm{kg}$ body wt at $11: 00$, respectively. The occurrence of ovulation was checked next morning. As shown in Table 1 and cited in the result again, injection of reserpine at the dosage of $1 \mathrm{mg} / \mathrm{kg}$ body wt, atropine $200 \mathrm{mg} / \mathrm{kg}$ body wt and PCPA $150 \mathrm{mg} / \mathrm{kg}$ body wt permitted a high percentage of animals to ovulate. The following experiment was performed employing these dosages of drugs.
Animals which were either pretreated or not with these drugs, received unilateral electrical stimulation in the dorsal hippocampus (HPC), lateral amygdaloid nucleus (1-AMYG) or central gray matter (CG) under light ether anesthesia through concentric bipolar stainless steel electrode which was located stereotaxically with the aid of atlas of Albe-Fessard et al. (1966). Immediately after the insertion of electrodes, monophasic square wave pulses with a frequency of $100 \mathrm{~Hz}$ was delivered for $30 \mathrm{~min}$ at 30 $\mathrm{sec}$ periods alternating with $30 \mathrm{sec}$ rest periods. The parameter for stimulation of the HPC was $100 \mu \mathrm{A}$ with $0.1 \mathrm{~ms}$ pulse duration and that for the 1-AMYG and CG was $300 \mu \mathrm{A}$ with $0.5 \mathrm{~ms}$ duration. Sham-stimulation was performed by insertion of electrodes into the frontal cortex for $30 \mathrm{~min}$ without delivering the current. These procedures were performed between 13:00 and 14:00, and ether anesthesia during this period was previously shown not to block spontaneous ovulation (Kawakami et al., 1972). Additional animals were served as the control without any of those procedures.

A group including the non-treated control, shamstimulated or stimulated animals with or without pretreatment of those drugs were autopsied by the decapitation at 18:00 on the same day except for several animals decapitated at 12:00. Blood samples were collected from the trunk and the sera separated by centrifugation were kept frozen until assayed. Another group of animals stimulated in the HPC or 1-AMYG was left until the next morning to be autopsied for the confirmation of ovulation. The brains were fixed in $10 \%$ formalin solution and studied microscopically in order to verify the sites of stimulation. Figures 5 and 6 show the sites of electrodes used.

The assay procedure of IH, FSH and prolactin was based on the methods described by Niswender et al. (1968) and NIAMDD instructions. The amounts of $\mathrm{LH}, \mathrm{FSH}$ and prolactin were expressed in terms of NIH-LH-S1, NIH-FSH-S1 and prolactin-RP-1, respectively. The significance of differences between groups was calculated by Student's $t$-test. Ovulation was identified by the presence of ova in the dilated ampullae of the oviducts microscopically.

\section{Results}

1. Effect of electrical stimulation of the $H P C, l-A M Y G$ or $C G$ on the ovulatory response and on the ovulatory release of LH, FSH and prolactin.

As can be seen in Table 2, the electrical stimulation of the HPC was effective to inhibit spontaneous ovulation; 4 out of 9 
Table 1. Effect of varying dosage of reserpine, atropine and PCPA injected on the day of proestrus on the expected ovulation

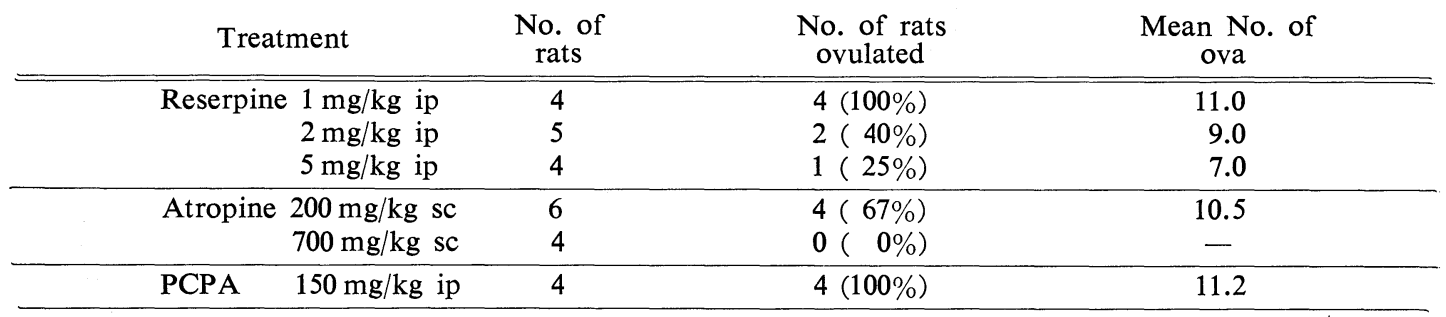

Table 2. Effect of electrical stimulation of the hippocampus (HPC) or lateral amygdala (1-AMYG) under reserpine or atropine treatment on the day of proestrus on the expected ovulation

\begin{tabular}{ccccc} 
Treatment & $\begin{array}{c}\text { Site of } \\
\text { stimulation }\end{array}$ & $\begin{array}{c}\text { No. of } \\
\text { rats }\end{array}$ & $\begin{array}{c}\text { No. of rats } \\
\text { ovulated }\end{array}$ & $\begin{array}{c}\text { Mean No. of } \\
\text { ova }\end{array}$ \\
\hline No treatment & HPC & 9 & $5(56 \%)$ & 10.5 \\
& 1-AMYG & 12 & $6(50 \%)$ & 10.2 \\
\hline Reserpine $1 \mathrm{mg} / \mathrm{kg}$ & HPC & 6 & $1(16 \%)$ & 9.5 \\
& 1-AMYG & 4 & $1(25 \%)$ & 8.0 \\
\hline Atropine $200 \mathrm{mg} / \mathrm{kg}$ & HPC & 5 & $4(80 \%)$ & 11.2 \\
& 1-AMYG & 4 & $0(0 \%)$ & - \\
\hline
\end{tabular}
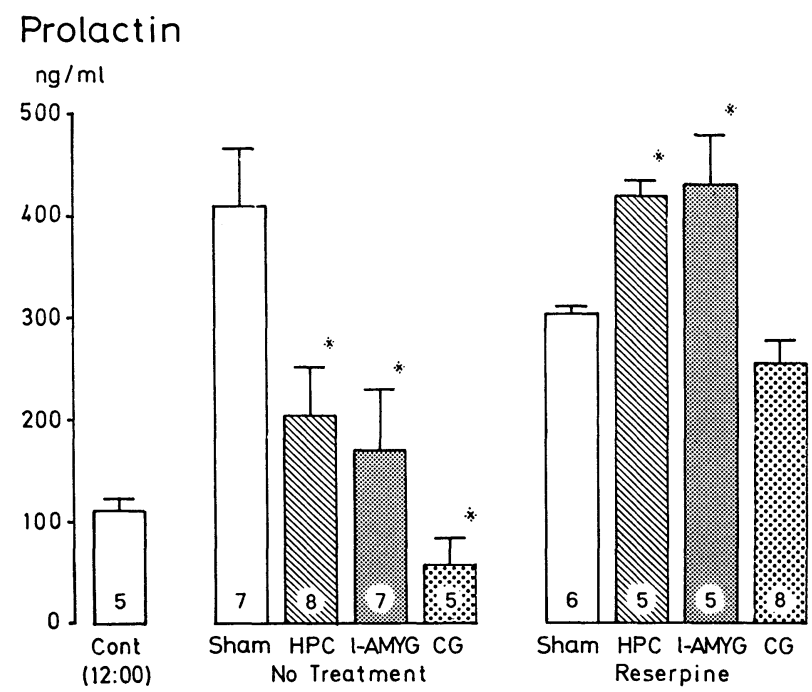

* $P<0.05$ vs Sham

Fig. 1. Effects of electrical stimulation of the hippocampus (PHC), lateral amygdala (1-AMYG) or central gray matter (CG) just before the critical period in the nontreated (No treatment), reserpine $(1 \mathrm{mg} / \mathrm{kg})$ or atropine $(200 \mathrm{mg} / \mathrm{kg})$ treated proestrous rats on serum concentration of $\mathrm{LH}$ at 18:00. Cont; non-treated at 12:00, sham; electrode inserted in the frontal cortex, but current not passed. 
animals stimulated failed to ovulate. The stimulation of the 1-AMYG also resulted in blockade of ovulation in 6 out of 12 animals stimulated.

The results from determination of $\mathrm{LH}$, FSH and prolactin concentrations in serum are shown graphically in Figures 1, 2 and 3. In the sham-stimulated rat, significant increases of LH, FSH and prolactin concentra- tions in serum were observed at 18:00 compared with those in the control rat at $12: 00$, indicating the occurrence of ovulatory gonadotropin release during the critical period. Levels of these three hormones were significantly lower at $18: 00$ in the rats which received electrical stimulation into the HPC, 1-AMYG or CG than those in the sham-stimulated rat.
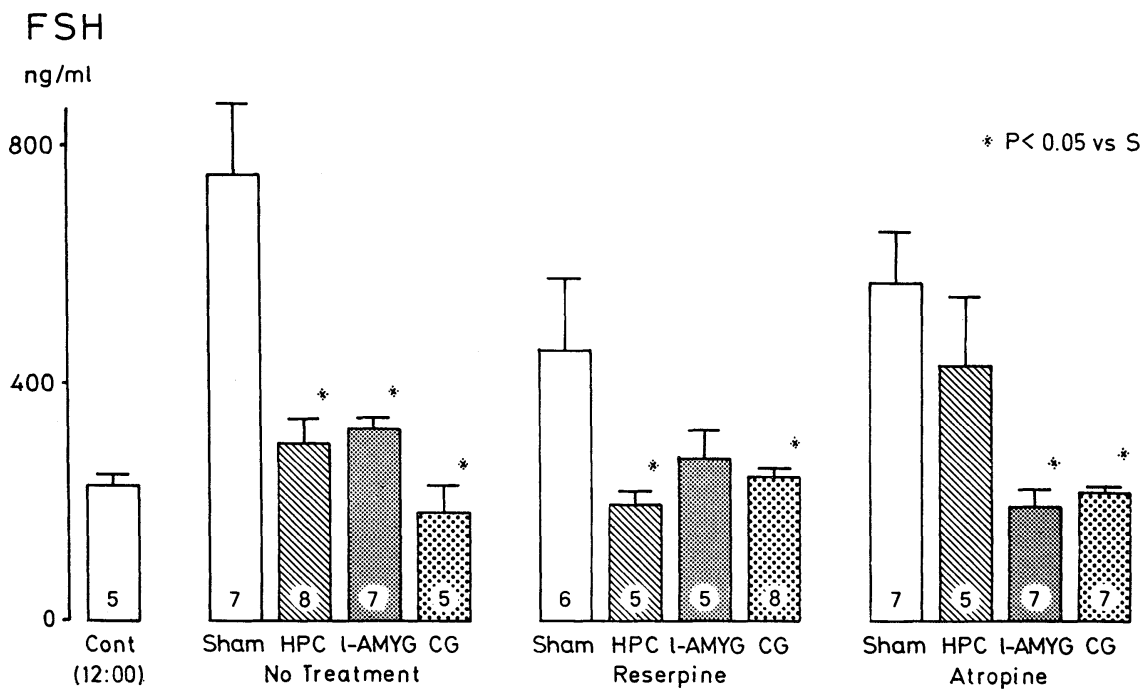

Fig. 2. Effects of similar stimulation as described for Figure 1 on FSH release.
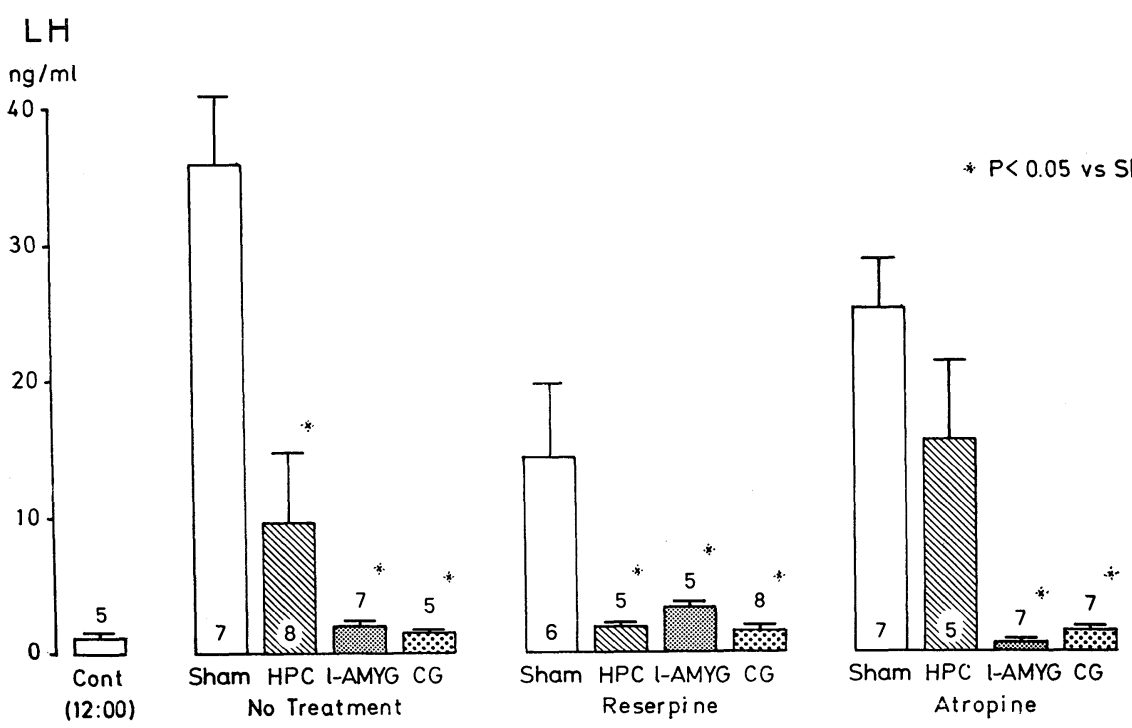

Fig. 3. Effects of similar stimulation as described for Figure 1 on prolactin release. 
2. Influence of reserpine, atropine or PCPA treatment on the inhibitory effect of electrical stimulation of the HPC, $l$ $A M Y G$ or $C G$ on ovulatory release of LH, FSH and prolactin.

Atropine: In agreement with previous reports (Everett, 1949, Sawyer et al., 1949), the relatively large dosage of atropine (700 $\mathrm{mg} / \mathrm{kg}$ body $\mathrm{wt}$ ) blocked ovulation, when it was administered about noon on the day of proestrus. Lower dosage $(200 \mathrm{mg} / \mathrm{kg}$ body $\mathrm{wt}$ ), however, interefered with ovulation only in 2 out of 6 animals tested (Table 1). As seen Figs. 1, 2 and 3, the increases of serum LH, FSH and prolactin levels in the atropine $(200 \mathrm{mg} / \mathrm{kg}$ body wt)-treated and shamstimulated animals at 18:00 compared with those levels in the control animal at 12:00 were significant. Serum LH, FSH and prolactin concentrations at 18:00 in the rat stimulated in the $1-\mathrm{AMYG}$ or $\mathrm{CG}$ were significantly low $(\mathrm{p}<0.05$ vs the sham-stimulated control), whereas in the rat stimulated in the HPC these concentrations showed no significant differences.

The blocking effect of the HPC stimulation on ovulation was restrained by pre- treatment with atropine at the dosage of $200 \mathrm{mg} / \mathrm{kg}$ body wt, since a high percentage of the rat stimulated in the HPC ovulated ( $80 \%$ vs $56 \%$ in the rat with no treatment). By contrast, in the rats stimulated in the 1-AMYG with atropine pretreatment ovulation was blocked (Table 2).

Reserpine: In the rat which received ip injection of reserpine at the dosage of $5 \mathrm{mg} / \mathrm{kg}$ or $2 \mathrm{mg} / \mathrm{kg}$ body wt between 11:00 and $11: 30$ on the day of proestrus, ovulation did not occur in 3 out of 4 , and in 3 out of 5 animals, respectively (Table 1). A dosage of $1 \mathrm{mg} / \mathrm{kg}$ body wt failed to interfere with ovulation, although the increases of serum LH, FSH and prolactin concentration at 18:00 in the sham-stimulated rat were slightly reduced compared with those levels in the non-treated and sham-stimulated rat. Electrical stimulation into the HPC, 1-AMYG or CG under reserpine treatment at the dosage of $1 \mathrm{mg} / \mathrm{kg}$ body wt was effective to decrease the serum concentrations of $\mathrm{LH}$ and FSH at 18:00, as was in the rat stimulated without any pretreatment. Whereas, the serum concentration of prolactin was higher $(p<0.05)$ at $18: 00$ in the rat stimulated in

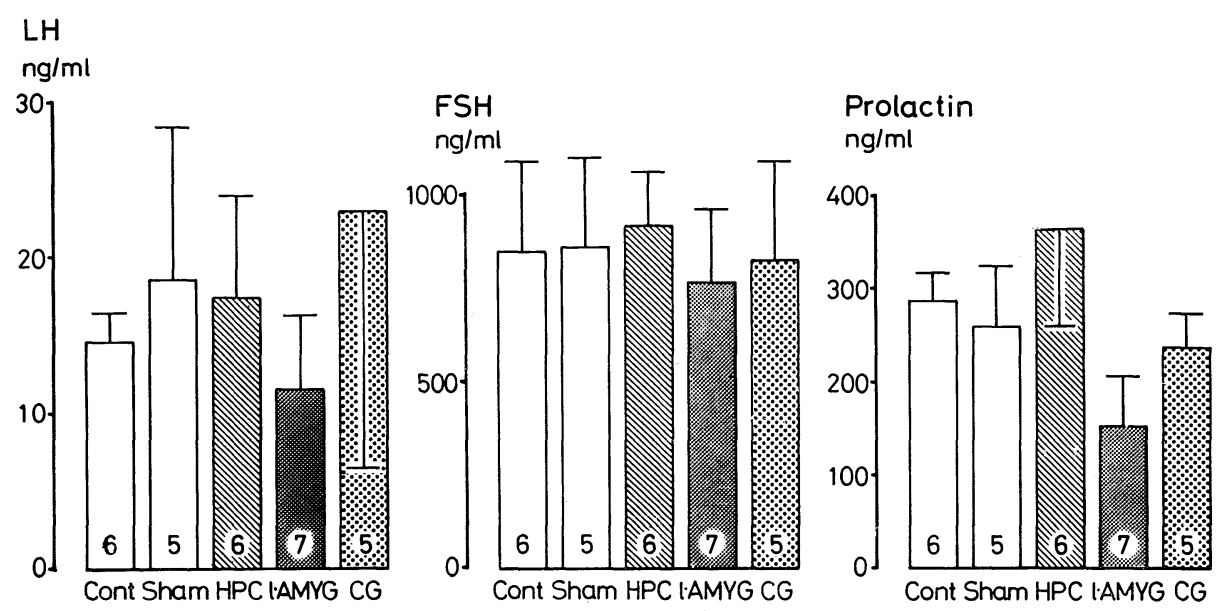

Fig. 4. Effects of electrical stimulation of the HPC, 1-AMYG or CG before the critical period in the p-chlorophenylalanine $(150 \mathrm{mg} / \mathrm{kg})$-treated proestrous rats on serum concentrations of LH, FSH and prolactin at 18:00. Cont; non-treated, sham; electrode inserted in the frontal cortex, but current, not passed. 
the HPC or the 1-AMYG than that in the sham-stimulated rat. No significant difference was seen in the prolactin concentration at 18:00 between the CG-stimulated and sham-stimulated animals (Fig. 3).

The electrical stimulation of the HPC or

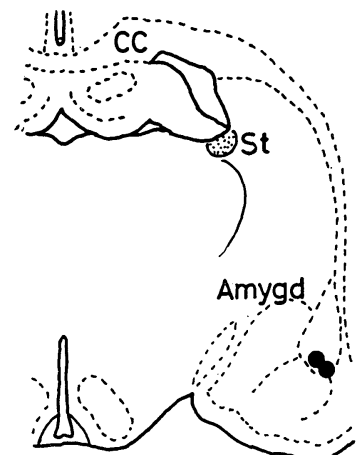

A 6.0

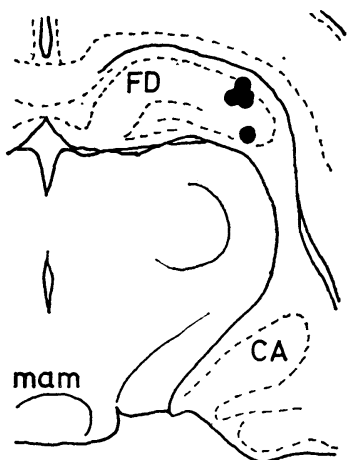

A 4.0

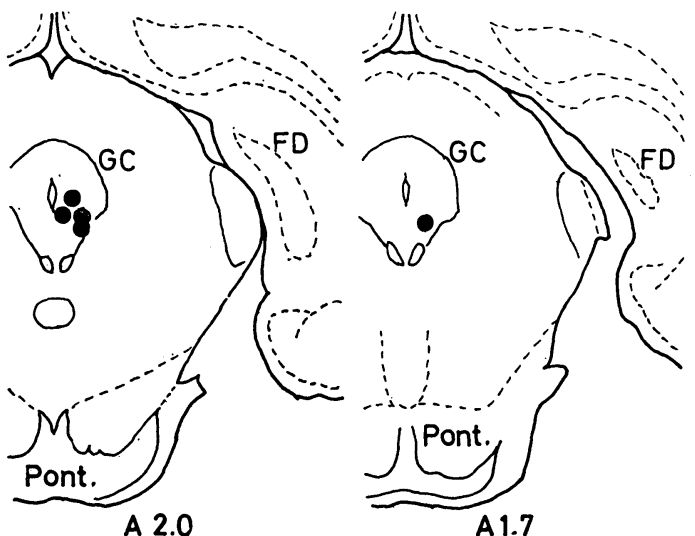

Fig. 5. Sites of electrodes for the stimulation in the non-treated rat.
1-AMYG was effective in preventing spontaneous ovulation even in the rat treated with reserpine at a dosage of $1 \mathrm{mg} / \mathrm{kg}$ (Table 2).

PCPA: Injection of PCPA at the dosage of $150 \mathrm{mg} / \mathrm{kg}$ at $11: 00$ on the day of proestrus exerted no influence on ovulation (Table 1). There were no significant difference between the serum LH, FSH and prolactin levels in the non-treated control rat and those in the PCPA-treated sham-stimulated rat (Fig. 4). Stimulation of the HPC, 1-AMYG or CG under PCPA treatment did not reduce the serum concentration of those three hormones at $18: 00$.
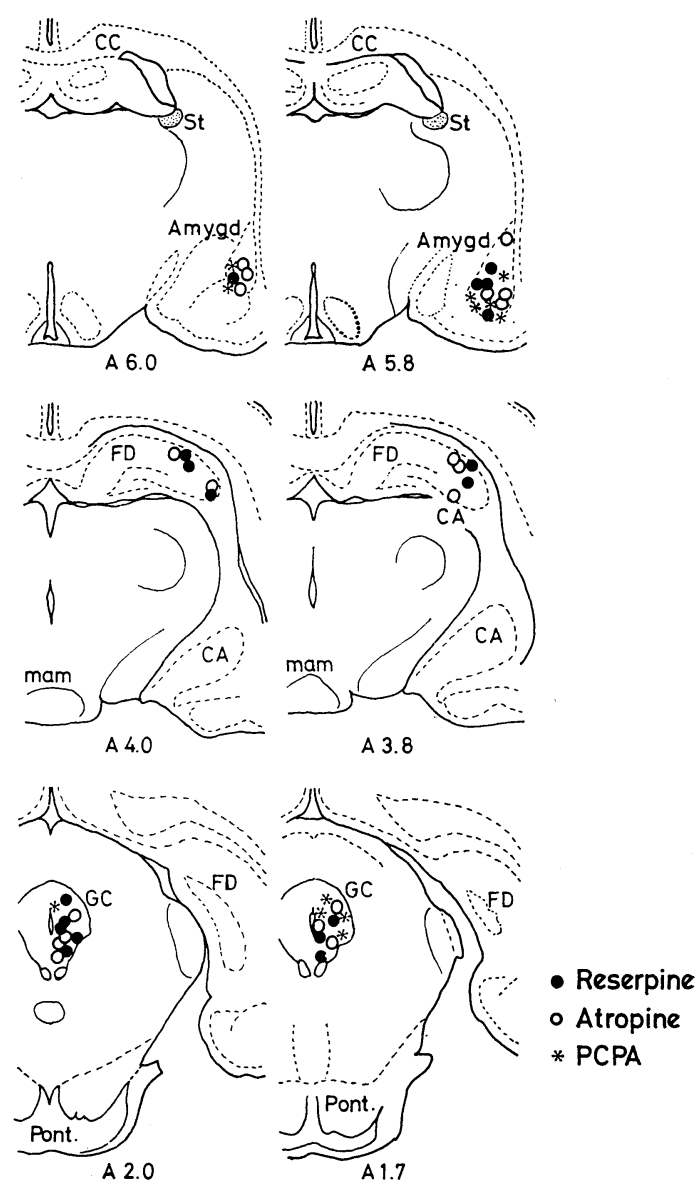

Fig. 6. Sites of electrodes for the stimulation under the reserpine, atropine or p-chlorophenylalanine (PCPA) treatment. 


\section{Discussion}

The results of the present study the electrical stimulation of the HPC, 1-AMYG or $C G$ just before the critical period on the day of proestrus inhibits the ovulatory release of $\mathrm{LH}$ and $\mathrm{FSH}$ are in agreement with previous reports (Velasco and Taleisnik, 1969; Carrer and Taleisnik, 1970; Kawakami, et al., 1972; Kawakami and Kimura, 1975a).

In the present experiment using various pharmacological drugs, it was demonstrated that pretreatment with atropine or PCPA abolished the inhibitory action of the HPC stimulation on LH and FSH release, whereas that with reserpine did not. The inhibitory action of the 1-AMYG or CG stimulation was abolished by pretreatment with PCPA, but not with reserpine or atropine. Atropine selectively antagonizes acetylcholine at the site where acetylcholine has muscarinic action, and PCPA at a high dose depletes both serotonin and catecholamine contents in the brain (Miller et al., 1970), whereas at a low dose it depletes selectively serotonin (Koe and Weissman, 1966). It is assumed, therefore, that the normal maintenance of both cholinergic and serotonergic neural links for the expression of the HPC inhibition, and of serotonergic link for the expression of the 1-AMYG or CG inhibition is necessary.

It could not be clarified in the present experiment, however, whether these cholinergic and/or serotonergic neuronal links were required at the site of stimulation or for the transmission of impulses made by the stimulation to the LH-release neural elements. The significant amount of 5-hydroxytryptamine (5-HT) is found in the mammalian brain, and it has early been noted that the HPC contains a high concentration of serotonin, and that even the piriform cortex and AMYG contain more serotonin than the hypothalamus (Paasonen et al., 1957). More recent studies indicate that nerve cells in the lower brain stem such as the dorsal raphe nuclei and central gray matter give rise to 5-HT stored in the diencephalon and telencephalon through their ascending axons, and, in the preoptic area, septum diagonal bands, AMYG and HPC, 5-HT terminals have been observed, but 5 -HT cell bodies have not (Fuxe, 1965a, b; Anden et al., 1966; Ungerstedt, 1971; Kuhar et al., 1972). Those seem to indicate that the serotonin stored in those nervous system is profoundly related to the activity of the HPC and AMYG as well as the CG itself. In fact, axo-somatic serotonin-containing synapses on AMYG neurons whose firing rates sharply decrease (Eidelberg et al., 1967) and seizure discharges in the HPC EEG (Kaneko et al., 1975) after administration of serotonin precursors were reported. A similar possibility can be proposed to the cholinergic nervous system. The HPC is rich in cholinesterase, receiving cholinesterase containing fibers which ascend from the brain stem via the medial septal nucleus and nucleus of the diagonal bands (Shute and Lewis, 1966), and thus, the HPC neuronal activity is highly affected by administration of acetylcholine, eserine or atropine (Salmoiraghi and Stefanis, 1966; Green et al., 1960). It was reported as well that especially the lateral basal and basal posterior AMYG show intense acetycholinesterase activity (Jacobowitz and Palkovits, 1974). However, the HPC and AMYG, both do not contain cells with such activity (Shute and Lewis, 1966). Those findings also indicate that the cholinergic inputs influence the activity of the HPC and AMYG.

The possibility that cholinergic and/or serotonergic mechanisms are involved in the transmission of inhibitory influence from the stimulation sites cannot be excluded. This seems most apparent for the CG, which has direct serotonergic connections with the hypothalamus through the medial forebrain bundle (MFB; Dahlstrom and Fuxe, 1964). However, the fact that the CG stimulation was 
effective to inhibit $\mathrm{LH}$ and FSH release under reserpine treatment inducing both catecholamine and serctonin depletions indicates, on the other hand, an implication of cholinergic mechanism as well. Carrer and Taleisnik (1972) suggested two available pathways to the hypothalamus; one directly through the dorsal longitudinal fasciculus and the other via the MFB-hypocampus-corticohypothalamic tract, and when one is lesioned the stimulation effect reaches the hypothalamus through the other one. The fornical fibers, which themselves do not contain cholinesterase, project to the anterior limbic area, nucleus accumbens, nucleus of anterior commisure, whose cells are rich in cholinesterase (Lewis and Shute, 1967), and cholinesterase activity is also high in the supraoptic nucleus, medial preoptic area, septal nucleus, and arcuate nucleus (Jacobowitz and Palkovits, 1974 ; Meszaros et al., 1969), which has been proved to receive projections from the HPC (Raisman and Field, 1971; Heimer and Nauta, 1969; Nauta, 1956). Since under the treatment with reserpine, at such dosage that is not enough to prevent ovulatory neural mechanism from operating, the HPC stimulation was also effective to inhibit ovulatory release of $\mathrm{LH}$, it may be possible that the HPC impulses reach such cholinergic mechanism through the fornical, presumably, catecholaminergic fibers (Reivich and Glowinski, 1967). Supporting this, the inhibition by the HPC stimulation on the firing rate of arcuate neurons was mimicked by iontophoretic application of acetylcholine (Kawakami and Sakuma, 1975). If that were the case, the blockade of HPC inhibitory effect by atropine treatment would be due to blocking of this cholinergic transmission. The mechanism for transmission of the 1-AMYG inhibition is obscure, since neither atropine or reserpine prevented the action. The possibility is that the inhibition of 1AMYG exerts an effect directly on the medial AMYG activity, which is a major ovulatory neural apparatus (Kawakami and Kimura,
$1975 b$ ), or reaches the hypothalamus through catecholaminergic pathway, namely the stria terminalis (Reivich and Glowinski, 1967; Kawakami and Kimura, 1975a) inspite of reserpine treatment; stimulation of the 1AMYG was effective to inhibit electrical activity in the medial preoptic area and arcuate nucleus (Kawakami et al., 1974a).

It was reported that atropine interfered with ovulation when given before the critical period (Everett, 1949; Sawyer et al., 1949), and also inhibited the rise in plasma LH before ovulation or after castration (Libertun and McCann, 1973; Kamberi, 1973). Those seem to suggest that cholinergic neurons are involved in the $\mathrm{LH}$ release mechanism in a stimulatory manner. From the present experiment, however, cholinergic mechanism appears to play a role in the conduction of HPC inhibitory influence on the LH release. Libertun and McCann (1974) recently reported that the immediate effect of muscarinic drugs injected sc was a suppression in the release of both LH and prolactin, although a delayed one was the facilitation. In our related experiment, it was observed that injection of anticholinesterase on the day before proestrus blocked the expected ovulation (Kimura, unpublished). Further studies are needed for determining the exact role of cholinergic mechanism in the control of gonadotropin release. In contrast, the majority of the experimental results shows that serotonin acts as an inhibitor of gonadotropin release. Subcutaneous or intraperitoneal injection of serotonin was found to inhibit spontaneous and PMSinduced ovulation in adult and immature rats, respectively (O'Steen, 1965; Endersby et al., 1970), and intraventricular administration of 5-HT inhibited even basal secretion of LH and FSH (Kamberi, 1973; Schneider and McCann, 1970). The results of the present experiment indicate that changes of the brain serotonin content significantly alter the activity of areas inhibitory to gonadotropin release, as well as the 
activity of effector cells of serotonergic neurons may be directly modified; implantation of 5-HT in the medial basal hypothalamus effectively blocked the ovulation (Kawakami et al., unpublished), and that into the medial forebrain bundle inhibited the induced ovulation in immature rats (Wilson, 1974).

Curiously, the inhibitory action of the HPC, 1-AMYG or CG is exerted on the ovulatory release of prolactin, as well as on that of LH and FSH. The effective stimulation of the medial preoptic area, septal nucleus or medial AMYG to induce LH and FSH release inhibited the prolactin release (Clemens et al., 1971; Kawakami et al., 1974b). The latter finding and many other observations indicating the difference between control mechanism for $\mathrm{LH}$ release and that for prolactin release may suggest that ovulatory hormone release is the result of a coupled activation of both mechanisms. Therefore, it should be recognized that the inhibitory effect of electrical stimulation would be exerted on both mechanisms. In agreement with this, the alteration of stimulative effect under the treatment with atropine or PCPA indicates that similar chemical substances assumed to have the inhibitory action on $\mathrm{LH}$ and FSH release are required for the inhibition of prolactin release as well; both the cholinergic and serotonergic mechanisms for the HPC inhibition and serotonergic one for the $1-\mathrm{AMYG}$ and $\mathrm{CG}$ inhibition. It is suggested, therefore, that the inhibition on prolactin is merely a reflection of inhibition on the operation of ovulatory hormone release mechanim as a whole. It may not be that the inhibition exerts an effect separately on the ovulatory prolactin release mechanism. Supporting this is the fact that implantation of 5-HT into the arcuate median eminence region before the critical period on the day of proestrus blocked not only the release of $\mathrm{LH}$ and FSH but also that of prolactin (Kimura, Kawagoe and Kawakami, unpublished). In this sense, the inhibition through serotonergic mechanism, for instance, is not necessarily incompatible with the experiment results showing the facilitatory effect of 5-HT on specific prolactin release induced by estrogen in the ovariectomized rat or by suckling in the lactating rat (Kordon et al., 1973/4; Caligaris and Taleisnik, 1974).

Under reserpine treatment, however, a dissociation of the stimulative effect on prolactin release from that on LH and FSH release was observed. That is, the stimulation of the HPC, 1-AMYG or CG did not prevent, but rather facilitated, the prolactin release, inspite of the significantly inhibitory effect on $\mathrm{LH}$ and $\mathrm{FSH}$ release. These changes in LH, FSH and prolactin release by the stimulation are quite similar to those after administration of an ovulation-blocking dose of reserpine. Although the mechanism by which such different effect on $\mathrm{LH}$ and prolactin release was induced is unknown, it may be considered that the effect of a high dose of reserpine was in some manner mediated by the action of limbic structure, as well as that of the hypothalamus (Van Maanen and Smelik, 1968).

In the present experiment, there was no correlation between the inhibition of $\mathrm{LH}$ surge and ovulation. However, the measurement of serum LH concentration and the check of ovulation were performed in different animals respectively. Moreover, the electrodes were not always implanted into a strictly definite point even if in the same hippocampal region. Considering this experimental procedure, it might be difficult to discuss the correlation between the serum LH concentration and the blockage of ovulation. Further study is required to solve this problem. 


\section{Acknowledgements}

We would like to thank National Institute of Arthritis, Metabolism and Digestive Disease, U.S.A. for supplying materials for the radioimmunoassay.

This study was supported by grant from the Ministry of Education, Japan.

\section{References}

Albe-Fessard, D., F. Stutinsky and S. Libouban. Atlas Stereotaxique du Diencephale du Rat Blanc, Centre National de la Recherche Scientifique, Paris (1966).

Anden, N. -E., A. Dahlstrom, K. Fuxe, K. Larsson, L. Olson and U. Ungerstedt (1966). Acta Physiol. Scand. 67, 313.

Caligaris, L. and S. Taleisnik (1974). J. Endocr. $62,25$.

Carrer, H.F. and S. Taleisnik (1970). J. Endcr. 48, 527.

Carrer, H.F. and S. Taleisnik (1972). Brain Res. 38, 299.

Clemens, J.A., C.J. Shaar, J.W. Klebber and W.A. Tandy (1971). Exptl. Brain Res. 12, 250.

Coppola, J.A. Frontiers in Neuroendocrinology (edit. by L. Martini and W.F. Ganong) Oxford Univ. Press, N.Y. p. 129 (1971).

Dahlström, A. and K. Fuxe (1964). Acta Physiol. Scand. Suppl. 62, 1.

Eidelberg, E., G.P. Goldstein and L. Deza (1967). Brain Res. 4, 73.

Endersby, C.A., J.M. Robson, F.M. Sullivan and C. Wilson (1970). J. Endocr. 48, 13.

Everett, J.W., C.H. Sawyer and J.E. Markee (1949). Endocrinology 44, 234.

Fuxe, K. (1965a). Z. Zellforsch. 65, 573.

Fuxe, K. (1965b). Acta Physiol. Scand. Suppl. 247, 36.

Green, J.D., D.S. Maxwell, W.J. Schindler and C. Stumpf (1960). J. Neurophysiol. 23, 403.

Heimer, L. and W.J.H. Nauta (1969). Brain Res. 13, 284.

Hökfelt, T. and K. Fuxe. Brain-Endocrine Interaction. Median Eminence: Structure and Function (edit. by K.M. Knigge, D.E. Scott and A. Weindle) S. Karger, Basel p. 181 (1972).

Jacobowitz, D.M. and M. Palkovits (1974). J. Comp. Neurol. 157, 13.

Kamberi, I.A. (1973). Recent Progr. Brain Res. 39, 261.

Kamberi, I.A., R.S. Mical and J.C. Porter (1971). Endocrinology 88, 1288.

Kaneko, Y., H. Kumashiro, T. Aono, K. Watanabe, S. Nakanishi and M. Kaneko (1975). Med. \& Biol. 91, 45 (in Japanese).
Kawakami, M. and F. Kimura (1975a). Endocrinol. Japon. 22, 61.

Kawakami, M. and F. Kimura. Neurobiology of CNS-Hormone Interactions. Anatomical Neutroendocrinology. S. Karger, Basel (1975b in press).

Kawakami, M., F. Kimura and N. Konda. Proc. Symp. on "Neuroendocrine Regulation of Fertility" in India 1974. S. Karger, Basel (1974 in press).

Kawakami, M., F. Kimura and K. Wakabayashi (1972). Endocrinol. Japon. 20, 59.

Kawakami, M., F. Kimura and Yanase. Biological Rhythms in Neuroendocrine Activity (edit. by M. Kawakami) Igakushoin, Tokyo, p. 167 (1974).

Kawakami, M. and Y. Sakuma (1975). Neuroendocrinology (submitted for publication).

Kawakami, M., E. Terasawa, F. Kimura and K. Kubo. Proc. Congr. on "Hormone and Brain Function" in Budapest 1971. Academicai Kiado, Budapest (1973).

Kimura, F. and M. Kawakami (1968). Folia Endocrin. Japon. 43, 1059.

Koe, B.K. and A. Weissman (1966). J. Pharm. and Expt. Therap. 154, 499.

Kordon, C., C.A. Blake, J. Terkel and C.H. Sawyer (1973/4). Neuroendocrinology 13, 213.

Kuhar, M., G.K. Aghajanian and R.H. Roth (1972). Brain Res. 44, 165.

Labhsetwar, A.P. (1961). Acta Endocr. Copenh. 68, 334.

Lewis, P.R. and C.C.D. Shute (1967). Brain 90, 521.

Libertun, C. and S.M. McCann (1973). Endocrinology 92, 1714.

Libertun, C. and S.M. McCann (1974). Proc. Soc. Expt. Biol. Med. 147, 498.

Maanen, J.H. van and P.G. Smelik (1968). Acta Physiol. Pharmacol. Neerl. 14, 519.

McCann, S.M., P.S. Karla, A.O. Donoso, W. Bishop, H.P.G. Schneider, C.P. Fawcett and L. Krulich. Brain-Endocrine Interaction. Median Eminence : Structure and Function (edit. by K.M. Knigge, D.E. Scott and A. Weindle) S. Karger, Basel p. 224 (1972).

Meszaros, T., I.J. Csuri, J. Hazas and M. Palkovits (1969). Acta Morph. Acad. Sci. Hung. 17, 201.

Miller, F.P., R.H. Cox, Jr., W.R. Snodgrass and R.P. Maickel (1970). Biochem. Pharmac. 19, 435.

Nauta, W.J.H. (1956). J. Comp. Neurol. 104, 247.

Niswender, G.D., A.R. Midgley, Jr., S.E. Monroe and L.E. Reichert, Jr. (1968). Proc. Soc. Exp. Biol. Med. 128, 807.

O'Steen, W.K. (1965). Endocrinology 77, 937.

Paasonen, M.K., P.D. MacLean and N.J. Giarman (1957). J. Neurochem. 1, 326.

Raisman, G. and P.M. Field. Frontiers in Neuroendocrinology (edit. by L. Martini and W.F. Ganong) Oxford Univ. Press, N.Y. p. 3 (1971).

Reivich, M. and J. Glowinski (1967). Brain 90, 633.

Salmoiraghi, G.C. and C.N. Stefanis (1966). Arch. Ital. Exp. Biol. 103, 705. 
Sawyer, C.H. (1975). Neuroendocrinology 17, 97.

Sawyer, C.H., J.E. Markee and J.W. Everett (1949).

Proc. Soc. Exp. Biol. Med. 71, 670.

Schneider, H.P.G. and S.M. McCann (1970). Endocrinology 86, 1127.

Shute, C.C.D. and P.R. Lewis (1966). Z. Zellforsch. $69,334$.
Ungerstedt, U. (1971). Acta Physiol. Scand. Suppl. $367,1$.

Velasco, M.E. and S. Taleisnik (1969). Endocrinology $85,1154$.

Wilson, C.A. (1974). Adv. Drug Res. 8, 119.

Wilson, C.A. and P.G. McDonald (1974). J. Endocrin. $60,253$. 